\title{
Suboptimal care in a case of severe hyponatremia in an elderly male patient in the emergency department. A three-question guide for basic assessment and treatment of hyponatremia
}

\author{
Jordi Liesveld ${ }^{*}$ \\ Intensivist, Hospital Rivierenland, Tiel, Netherlands
}

\begin{abstract}
Hyponatremia is a common medical disorder with high mortality and morbidity. Extensive guidelines are developed by internal medicine and critical care specialists. However, every physician should be familiar with initial assessment and treatment of hyponatremia. A case of a severe hyponatremia presenting to an emergency room is described where care was suboptimal. This case illustrates that diagnosis and treatment are not always straight forward. Three questions are proposed to guide physicians in the immediate care of hyponatremic patients.
\end{abstract}

\section{Introduction}

Hyponatremia $(\mathrm{HN})$ is a common metabolic disorder in up to $30 \%$ of hospitalized patients and might be underreported [1,2]. The most frequent cause of $\mathrm{HN}$ is the syndrome of inappropriate antidiuretic hormone (SIAD). HN is associated with high in-hospital and longterm mortality and high morbidity [1-3]. Even mild HN may lead to falls and attention deficits in the elderly [4]. Guidelines are traditionally developed by internal medicine- and critical care societies, based on sparse scientific evidence [5-7]. HN can be categorized according severity ( severe or profound $<120 \mathrm{mmol} / \mathrm{l}$, moderate $120-130 \mathrm{mmol} / \mathrm{l}$, mild 130-135 mmol/l), tonicity (hypotonic, isotonic, hypertonic), volume status (hypovolemic, euvolemic, hypervolemic), duration (acute $<48$ hours of chronic $>48$ hours) or symptomology. The various guidelines present different diagnostic and therapeutic algorithms, and contain extensive expert diagnostic options like co-peptin, fractional excretion of urea of uric acid and treatment options like demeclocycline, urea, vaptans [5,7-10]. Despite these guidelines HN remains challenging to diagnose and treat, demonstrated by the reported suboptimal care [11]. Complicating factors include the presence of multiple contributing factors (e.g. malignancies, drugs, low sodium intake) [12]. Also, classifying HN based on the recommended physiological assessment of volume status may lead to a wrong diagnosis [13].

The responsibility for treating HN does not lie solely with internal medicine or critical care specialists. Every physician, especially in the field of emergency medicine, should be familiar with the urgent diagnostic and treatments steps in HN. A case is described of severe $\mathrm{HN}$ in an elderly male patient, in which initial care was suboptimal. Three questions are formulated, and related to recent literature, which may guide every physician in assessing an hyponatremic patient.

\section{Case report}

A male octogenarian was referred to the emergency department because of general deterioration (day 0 ). His medical history mentioned an ischemic cerebrovascular accident and hypertension. His prescribed home medications were acetylsalicylic acid, atorvastatin, perindopril/ indapamide; which were last ingested on the day before admission. He did not drink alcohol but had smoked more than fifty pack years. The last months he had no appetite and lost 20 kilograms in weight. In the last week there was almost no food intake; his fluid intake seemed adequate. He became increasingly confused and had fallen two times in the last week. Also, the patient became incontinent for urine. Blood testing showed: sodium $103 \mathrm{mmol} / \mathrm{l}$, potassium 4,6 mmol/l, magnesium $0,6 \mathrm{mmol} / \mathrm{l}$, corrected calcium $2,2 \mathrm{mmol} / \mathrm{l}$, phosphate $0,98 \mathrm{mmol} / \mathrm{l}$, glucose $6,1 \mathrm{mmol} / \mathrm{l}$, creatinine $102 \mathrm{umol} / \mathrm{l}$, hemoglobin $8,2 \mathrm{mmol} / \mathrm{l}$, CRP $14 \mathrm{mg} / \mathrm{l}$ with a mild leukocytosis. At physical examination the patient was restless and disorientated in time, place and person. His blood pressure was normal; there were no evident signs of hypovolemia or fluid overload. A CT-scan of the brain showed no posttraumatic or other lesions. Catherization showed a urinary retention of 1000 milliliter.

For a symptomatic HN $100 \mathrm{ml}$ of sodium chloride 3\% (30 mg/ ml) was administered. Also, 500 milliliter of sodium chloride $0,9 \%$ was infused. Because of the severity of the sodium disturbance the Intensive Care Unit (ICU) was consulted for correcting the sodium level and to monitor for adverse events. Next adjuvant testing was performed, which showed serum osmolality of $221 \mathrm{mosmol} / \mathrm{kg}$, urine osmolality $378 \mathrm{mosmol} / \mathrm{kg}$ and urine sodium level of $38 \mathrm{mmol} / \mathrm{l}$. In the ICU the patient was put on fluid restriction of 1000 milliliter per day. The ACE-inhibitor and diuretic were stopped. Because of the severity of $\mathrm{HN}$ and because the mild cognitive symptoms possibly related to the

^Correspondence to: Jordi Liesveld, Netherlands, E-mail: Jordi.liesveld@gmail. com

Received: July 09, 2019; Accepted: July 15, 2019; Published: July 18, 2019 
Liesveld J (2019) Suboptimal care in a case of severe hyponatremia in an elderly male patient in the emergency department. A three-question guide for basic assessment and treatment of hyponatremia

low sodium level, a slow continuous infusion of $\mathrm{NaCl} 3 \%$ was started, aiming for a $5-8 \mathrm{mmol} / \mathrm{l}$ increase in the first 24 hours (Figure 1). After 24 hours serum sodium level was $109 \mathrm{mmol} / \mathrm{l}$. On the second day of admission after another 14 hours the sodium level was $115 \mathrm{mmol} / \mathrm{l}$. The sodium chloride $3 \%$ infusion had been decreased and stopped in two days. Patient was transferred to the general ward on day 2 , his cognitive deficits were minimal. A fluid restriction was maintained of 1500 milliliter per day, the sodium level slowly increased to $130 \mathrm{mmol} / \mathrm{l}$. On day 9 he was discharged from the hospital. During admission in the ICU no somatic cause was found for the HN: X-ray of the thorax was normal PSA was normal, as were kidney-adrenal-thyroid-liver functions. Follow up will take place on an outpatient basis.

\section{Discussion}

Every physician should be familiar with the initial urgent diagnostic and treatment steps for HN. Three important questions, which are described below, can guide the physician.

\section{Is the hyponatremia symptomatic?}

The most important complication of $\mathrm{HN}$ is cerebral edema due of movement of water following an osmotic gradient into the cell. After 48-hour active osmotic particles are transported out of the cell as a compensating mechanism [6]. Therefore, an acute decrease in sodium level is more likely to cause edema. To cause cell swelling hyponatremia has to be hypotonic, in isotonic or hypertonic hyponatremia other osmoles are present (e.g. glucose, glycine) which attract water and dilute the serum sodium. Low serum osmolality is often used to exclude isotonic or hypertonic hyponatremia; however, serum osmolality also measures urea which is not an osmole. When serum osmolality is not available the formula for effective osmolality can be used: Effective osmolality $(\mathrm{mmol} / \mathrm{kg} \mathrm{H} 2 \mathrm{O})=2 \times($ serum sodium $(\mathrm{mmol} / \mathrm{l})+$ serum $\mathrm{K}$ $(\mathrm{mmol} / \mathrm{l}))+$ serum glycaemia $(\mathrm{mmol} / \mathrm{l})[6]$. Also, pseudohyponatremia might be excluded, using serum for example triglycerides or protein levels.
Hypotonic hyponatremia can cause a spectrum of signs and symptoms ranging from life threatening to subtle cognitive disorders or can even be asymptomatic [8,14]. A severe complication of overcorrecting serum sodium level is osmotic demyelination syndrome. Whether immediate treatment is indicated, depends on the severity of symptoms. Risk of edema is deemed more severe than the risk of osmotic demyelination in case of severe symptoms. Guidelines and treatment algorithms offer various and different categorizations of symptoms based on severity [5-7]. Well known examples of severe symptoms are coma and convulsions. But less clear are the patients with nausea, somnolence, confusion, cognitive deficits or headache. Vomiting, cardiorespiratory distress, seizures and coma are consequently rated as severe. Muscle rigidity is sometimes also rated as severe. Nausea without vomiting and headache are rated as moderately severe. Somnolence is rated as severe or moderate symptom depending on source. Confusion is categorized as moderate in some guidelines.

In case of severe symptoms guidelines and treatment algorithms recommend immediate administration of a bolus of sodium chloride $3 \%$, the recommended dosage varies from 100 to $150 \mathrm{ml}$ or $2 \mathrm{ml} / \mathrm{kg}$ (5-7). With persistent severe symptoms a bolus can be repeated twice; with a target increase of 4-6 mmol to reverse serious complications. Treatment recommendations differ in case of moderate severe symptoms, a single bolus of hypertonic saline or slow continuous infusion of hypertonic saline is advocated.

\section{Is the hyponatremia acute?}

As stated above acute $\mathrm{HN}$ is more likely to be (come) symptomatic due to cerebral edema. Because of the incomplete adaptation mechanism, the cut-off between acute and chronic HN is 48 hours. If the duration of hyponatremia is not documented, it is regarded as a chronic hyponatremia. With acute hyponatremia, adaptation of the brain is not completed and the risk for pontine demyelination might be. According to the European guideline a single infusion of $150 \mathrm{ml}$ sodium chloride $3 \%$ can be given [6]. In chronic HN the goals and

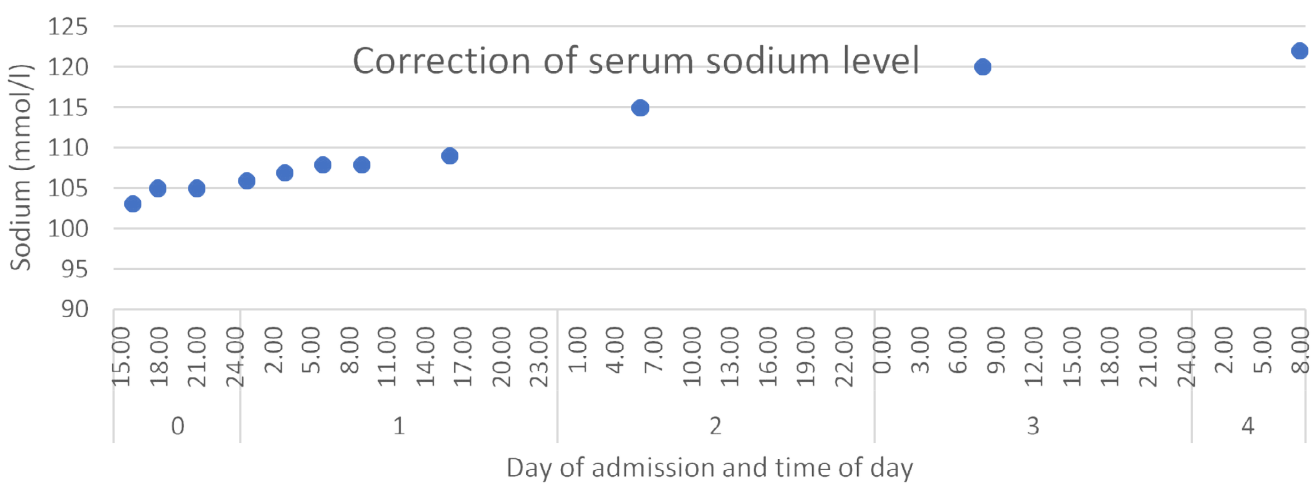

Figure 1. Rate of increase of sodium lever during the first five days of admission

Table 1. Three questions guiding initial assessment with basic diagnostic and treatment considerations

\begin{tabular}{|l|l|l|}
\hline Questions & Diagnostic considerations & Treatment considerations \\
\hline Is the hyponatremia symptomatic? & $\begin{array}{l}\text { Pseudohyponatremia, Alternative diagnosis, Serum } \\
\text { osmolality, Plasma glucose, Effective Osmolality }\end{array}$ & $\begin{array}{l}\text { Yes: } 100 \mathrm{ml}-2 \mathrm{ml} / \mathrm{kg} \text { bolus NaCl 3\%, up to three times in } \\
\text { severe symptoms } \\
\text { No: slow correction, cause specific }\end{array}$ \\
\hline Is the hyponatremia acute? & Documented serum sodium levels & $\begin{array}{l}\text { Yes: Faster correction, bolus NaCl 3\% or continuous } \\
\text { infusion } \\
\text { No: slow correction, cause specific }\end{array}$ \\
\hline What is the cause of the hyponatremia? & $\begin{array}{l}\text { Expert consultation, Serum and Urine electrolytes, Urine } \\
\text { osmolality, Liver- kidney- adrenal- thyroid insufficiency, } \\
\text { Drugs, Sodium intake } \\
\text { SIAD: infection, malignancy }\end{array}$ & $\begin{array}{l}\text { Cause-specific treatment: e.g. stop precipitating factors, fluid } \\
\text { restriction }\end{array}$ \\
\hline
\end{tabular}


Liesveld J (2019) Suboptimal care in a case of severe hyponatremia in an elderly male patient in the emergency department. A three-question guide for basic assessment and treatment of hyponatremia

limits of sodium level correction became more conservative over time, the limits are around $8-10 \mathrm{mmol} /$ day.

\section{What are the precipitating factors for hyponatremia?}

Hyponatremia is a heterogenous disorder with many possible causes. After the first questions are answered, the treatment of HN should be cause-specific. Syndrome of inappropriate antidiuretic hormone (SIAD) is the most frequent cause of hyponatremia, however, to diagnose SIAD other possible causes should be excluded. Also, SIAD can be caused by various underlying diseases $[8,15,16]$. Guidelines present various diagnostic algorithms using different clinical or laboratory parameters [5,7-9]. As stated earlier, the use of recommended clinical parameters might lead to wrong diagnoses. Also, patients may have multiple factors contributing to the, and the etiology might not become clear (immediately). After finding $\mathrm{HN}$ and after the immediate treatment steps, the diagnostic steps and correction of sodium levels are often under the responsibility of internal medicine of critical care specialists. However, basic investigations should be requested by every physician. Prescribed medication should be screened and drugs which may contribute to HN should be stopped. Table 1 contains diagnostic and treatment considerations for each question (Table 1).

Hereafter, the questions are applied to the described case about an older male patient with a severe hyponatremia.

\section{Is the hyponatremia symptomatic?}

Important basic tests were not performed before administering a bolus of hypertonic saline. Afterwards a low serum osmolality was found, and the effective osmolality was $227,6 \mathrm{mmol} / \mathrm{kg} \mathrm{H} 2 \mathrm{O}$. The patient was confused and disorientated, and these symptoms are generally not categorized as moderate. Moreover, the symptoms can also be explained as a delirium caused by the urinary retention. So, it can be argued whether the hypertonic sodium bolus should have been given, with potential pontine demyelination as severe complication. Another option is to stop precipitating factors and observe sodium levels, or to administer a slow continuous infusion.

\section{Is the hyponatremia acute?}

Since the duration of the hyponatremia is unknown, the disorders should be treated as a chronic. Regarding the duration of $\mathrm{HN}$, a bolus of hypertonic saline does not seem to be indicated.

\section{What are the precipitating factors for hyponatremia?}

Low blood and high urine osmolality and urine sodium levels are consistent SIAD, however low sodium intake and use of diuretic exclude a formal diagnosis of SIAD. The patient is treated with fluid restriction as first line treatment. Elderly should be screened for a malignancy as a precipitating cause. In this a case an X-ray did not show signs of pulmonary disease. Also, prostatic carcinoma seems unlikely due to low serum PSA-levels. A rare cause of SIAD described in literature is acute urinary retention [17]. Other factors might have contributed to the low sodium levels in this case are: low dietary sodium intake and the use of angiotensin converting enzyme inhibitor and thiazide-related diuretic. Kidney, adrenal, liver and thyroid testing were normal. This case points out that especially in elderly multiple factors may contribute to the development of $\mathrm{HN}$.

In this case important basic testing like serum osmolality, urine testing and liver-adrenal-thyroid function was not performed before administering hypertonic saline. Also, this case shows that it is not always clear if subtle or moderate symptoms are related to the $\mathrm{HN}$ and whether they are severe enough to administer hypertonic saline. Often multiple causes of $\mathrm{HN}$ can be found.

\section{Conclusion}

Every physician should be familiar with the initial diagnostic steps and urgent treatment of hyponatremia. Three questions can be used as guidance. Is the hyponatremia symptomatic? Is the hyponatremia acute? What are the precipitating factors for the hyponatremia?

\section{Acknowledgement}

None.

\section{Funding information}

No funding is received for this manuscript.

\section{Conflict of Interest}

The author has no conflict of interest.

\section{References}

1. Asadollahi K, Beeching N, Gill G (2006) Hyponatraemia as a risk factor for hospital mortality. QJM 99: 877-880. [Crossref]

2. Hao J, Li Y, Zhang X, Pang C, Wang Y, et al. (2017) The prevalence and mortality of hyponatremia is seriously underestimated in Chinese general medical patients: an observational retrospective study. BMC Nephrol 18: 328. [Crossref]

3. Winzeler B, Jeanloz N, Nigro N, Suter-Widmer I, Schuetz P, et al. (2016) Long-term outcome of profound hyponatremia: a prospective 12 months follow-up study. Eur J Endocrinol 175: 499-507. [Crossref]

4. Renneboog B, Musch W, Vandemergel X, Manto MU, Decaux G (2006) Mild chronic hyponatremia is associated with falls, unsteadiness, and attention deficits. Am J Med 119: 71.e1-8. [Crossref]

5. Overgaard-Steensen C, Ring $\mathrm{T}$ (2013) Clinical review: practical approach to hyponatraemia and hypernatraemia in critically ill patients. Crit Care 17: 206. [Crossref]

6. Spasovski G, Vanholder R, Allolio B, Annane D, Ball S, et al. (2014) Clinica practice guideline on diagnosis and treatment of hyponatraemia. Nephrology Dialysis Transplantation 29: i1-i39.

7. Verbalis JG, Goldsmith SR, Greenberg A, Korzelius C, Schrier RW, et al (2013) Diagnosis, Evaluation, and Treatment of Hyponatremia: Expert Pane Recommendations. Am J Med 126: S1-S42. [Crossref]

8. Dineen R, Thompson CJ, Sherlock M (2017) Hyponatraemia - presentations and management. Clin Med (Lond) 17: 263-269. [Crossref]

9. Hoorn EJ, Zietse R (2017) Diagnosis and Treatment of Hyponatremia: Compilation of the Guidelines. J Am Soc Nephrol 28: 1340-1349. [Crossref]

10. Spasovski G, Vanholder R, Allolio B, Annane D, Ball S, et al. (2017) Hyponatraemia diagnosis and treatment clinical practice guidelines. Nefrologia 37: 370-380. [Crossref]

11. Greenberg A, Verbalis JG, Amin AN, Burst VR, Chiodo JA, et al. (2015) Curren treatment practice and outcomes. Report of the hyponatremia registry. Kidney Int 88 : 167-177. [Crossref]

12. Hoorn EJ, Lindemans J, Zietse R (2006) Development of severe hyponatraemia in hospitalized patients: treatment-related risk factors and inadequate management Nephrol Dial Transplant 21: 70-76. [Crossref]

13. Fenske W, Maier SK, Blechschmidt A, Allolio B, Stork S (2010) Utility and limitations of the traditional diagnostic approach to hyponatremia: a diagnostic study. Am J Med 123: 652-657. [Crossref]

14. Nigro N, Winzeler B, Suter-Widmer I, Schuetz P, Arici B, et al. (2015) Symptoms and characteristics of individuals with profound hyponatremia: a prospective multicenter observational study. J Am Geriatr Soc 63: 470-475. [Crossref]

15. Harrois A, Anstey JR (2019) Diabetes Insipidus and Syndrome of Inappropriate Antidiuretic Hormone in Critically Ill Patients. Crit Care Clin 35: 187-200. [Crossref] 
Liesveld J (2019) Suboptimal care in a case of severe hyponatremia in an elderly male patient in the emergency department. A three-question guide for basic assessment and treatment of hyponatremia

16. Verbalis JG, Greenberg A, Burst V, Haymann JP, Johannsson G, et al. (2016) Diagnosing and Treating the Syndrome of Inappropriate Antidiuretic Hormone Secretion. Am J Med 129: 537.e9-537.e23. [Crossref]
17. Manappallil C, Josephine (2019) Symptomatic hyponatremia: A consequence of acute urinary retention due to benign prostatic hyperplasia. Indian $J$ Case Reports 5: 297-298.

Copyright: (C2019 Liesveld J. This is an open-access article distributed under the terms of the Creative Commons Attribution License, which permits unrestricted use, distribution, and reproduction in any medium, provided the original author and source are credited. 